East Tennessee State University

Digital Commons@ East Tennessee State University

ETSU Faculty Works

Faculty Works

7-1-2014

\title{
Pattern and Rate of Decline of a Population of Carolina Hemlock (Tsuga caroliniana Engelm.) in North Carolina
}

Foster Levy

East Tennessee State University, levyf@etsu.edu

Elaine S. Walker

East Tennessee State University

Follow this and additional works at: https://dc.etsu.edu/etsu-works

Part of the Plant Biology Commons, and the Plant Pathology Commons

\section{Citation Information}

Levy, Foster; and Walker, Elaine S.. 2014. Pattern and Rate of Decline of a Population of Carolina Hemlock (Tsuga caroliniana Engelm.) in North Carolina. Southeastern Naturalist. Vol.13(sp6). 46-60. https://doi.org/10.1656/058.013.s605 ISSN: 1528-7092

This Article is brought to you for free and open access by the Faculty Works at Digital Commons @ East Tennessee State University. It has been accepted for inclusion in ETSU Faculty Works by an authorized administrator of Digital Commons @ East Tennessee State University. For more

information, please contact digilib@etsu.edu. 


\section{Pattern and Rate of Decline of a Population of Carolina Hemlock (Tsuga caroliniana Engelm.) in North Carolina}

\section{Copyright Statement}

Copyright of Southeastern Naturalist is the property of Eagle Hill Institute. This document was published with permission from the journal. It was originally published in the Southeastern Naturalist. 


\title{
Pattern and Rate of Decline of a Population of Carolina Hemlock (Tsuga caroliniana Engelm.) in North Carolina
}

\author{
Foster Levy ${ }^{1, *}$ and Elaine S. Walker ${ }^{2}$
}

\begin{abstract}
We monitored a population of Carolina Hemlocks in northwestern North Carolina for four years to examine the rate and pattern of decline in response to infestation by Adelges tsugae (Hemlock Woolly Adelgid). Our yearly census of hemlock condition and severity of the adelgid infestation included trees of all sizes. We estimated declines in condition as the portions of the leaf canopy that were lost. Initially, infestation occurred throughout the population but was severe in only a small cluster of individuals. Within 1 year, the area of severe infestation increased in size to encompass $48 \%$ of the population. In another region of the population, there was a cluster of relatively healthy individuals comprised largely of seedlings. Of the 4 size-classes of trees, sapling-sized individuals experienced the highest rates of decline in condition. Most trees declined to poor health within 3 years of an observation of moderate to severe infestation.
\end{abstract}

\section{Introduction}

With the exception of upper Piedmont outlier populations, Tsuga caroliniana Engelm. (Carolina Hemlock) is endemic to the Blue Ridge physiographic province of the southern Appalachian Mountains from southwestern Virginia to northern Georgia (Jetton et al. 2008, Rentch et al. 2000). While in some areas, the 2 hemlock species of eastern North America - Carolina Hemlock and Tsuga canadensis (L.) Carrière (Eastern Hemlock) - exist in sympatry, artificial hybridization and DNAbased molecular data suggest a closer relationship of Carolina Hemlock to Asian hemlocks than to Eastern Hemlock (Bentz et al. 2002, LePage 2003, Pooler et al. 2002). Ecologically, Carolina Hemlock tends to inhabit drier and more exposed sites, such as rocky ridges overlain by acidic, sandy clay loam soils, than the shaded lowlands and moist coves preferred by Eastern Hemlock (Jetton et al. 2008).

Few studies have examined Carolina Hemlock population and community structure. At 2 locations where age structure was analyzed using tree cores-Bluff Mountain, Ashe County, NC, and Bottom Creek Gorge, Montgomery County, VAsome trees exceeded $30 \mathrm{~cm}$ diameter at breast height (dbh) and 220 years of age (Humphrey 1989, Rentch et al. 2000). There was a linear relationship between tree diameter and age at both locations. However, the pattern of seedling recruitment and the population age structure varied widely across populations. For example, populations at Linville Falls, NC, and 3 sites examined at Bluff Mountain had negative exponential age-class distributions characteristic of stable age distributions (Humphrey 1989, Levy et al. 2008). In contrast, the population at Bottom Creek

\footnotetext{
${ }^{1}$ Department of Biological Sciences, East Tennessee State University, Johnson City, TN 37614. ${ }^{2}$ Department of Internal Medicine, James H. Quillen College of Medicine, East Tennessee State University, Johnson City, TN 36514. *Corresponding author - levyf@etsu.edu.
} 
Gorge had a normal age distribution with a relative dearth of seedlings. Similarly, seedlings were absent or rare at 2 sites in eastern Tennessee (Levy et al. 2008). These studies pre-dated major impacts and loss of Carolina Hemlock trees due to Adelges tsugae Annand (Hemlock Woolly Adelgid [HWA]) infestations.

Whereas many studies have focused on the impact of HWA on Eastern Hemlock, relatively little quantitative information exists for impacts on Carolina Hemlock. The exception was a baseline study of HWA impacts on Carolina Hemlock in western North Carolina and eastern Tennessee in which each of 4 populations showed a spatial pattern of infestation and hemlock decline characterized by 1 or more clusters of diseased trees and clusters of healthy trees (Levy et al. 2008). Although congeneric with Eastern Hemlock, the rate and pattern of decline in response to HWA may differ between the species because Carolina Hemlock in the southern Appalachians tends to inhabit drier, more nutrient-poor sites (Humphrey 1989, Jetton et al. 2008). Further, the geographic range of Carolina Hemlock is largely restricted to the southern Appalachians, a region where decline in Eastern Hemlock has been most severe (Evans et al. 2011). The impending loss of natural populations of Carolina Hemlock and the paucity of quantitative information on population structure and HWA impacts will impede conservation planning and management efforts, including setting re-introduction targets.

The goal of this study was to examine the rate of Carolina Hemlock decline and the pattern of spread of HWA in a multi-year analysis of a single population. This approach was feasible because the study population was relatively small, with less than 200 individuals, and the spatial boundaries were well defined. Moreover, the population was isolated from other populations by a distance of at least $5 \mathrm{~km}$. We conducted annual monitoring and assessment of hemlock tree condition and HWA infestation metrics over a period of 4 years, commencing soon after HWA was first observed in the population.

\section{Field Site Description}

We selected a population of Carolina Hemlock where we could conduct annual demographic monitoring from 2007 to 2010 . The population is adjacent to the Fodder Stack Trail in Doughton Park, Allegheny and Wilkes County, NC on a narrow southeast-northwest-trending ridge $\left(81^{\circ} 10.126^{\prime} \mathrm{W}, 36^{\circ} 25.770^{\prime} \mathrm{N}\right)$ at $1100 \mathrm{~m}$ elevation (Fig. 1). Slopes on the ridge are negligible. The site is within the jurisdiction of the Blue Ridge Parkway and is located near Milepost 241. The overstory of the site is dominated by Carolina Hemlock with minor representation by Quercus montana Willd. (Chestnut Oak), Acer rubrum L. (Red Maple), Nyssa sylvatica Marshall (Blackgum), and Oxydendrum arboreum (L.) DC. (Sourwood). Where the stand is dense, few other woody species are present in the overstory or the understory. The census population varied from 101-138 individual Carolina Hemlocks, with differences in numbers largely dependent upon seedling turnover. The maximum dbh of Carolina Hemlock at the site was $30 \mathrm{~cm}$. This size corresponds to $75-175$ years of age based on the linear regression of age on dbh in Rentch et al. (2000) or to approximately 125 years of age based on the plot of dbh and age in Humphrey (1989). 
The study terminated when the infestation had progressed to the point where 1 tree had died and access to the site was limited by multi-year closure of the Blue Ridge Parkway for repairs.

\section{Methods}

\section{Population census}

We conducted a population census in early September each year, from 20072010. To assess spatial structure in the population, we noted the location of each individual as $\mathrm{x}$-axis coordinates along a 100-m transect that followed the spine of the ridge, with $y$-axis coordinates extending perpendicular to the transect for a maximum of $20 \mathrm{~m}$ on either side. This transect captured all Carolina Hemlocks except those on steep slopes off the ridge. Trees included in the census accounted for $>90 \%$ of the individuals in the population that were larger than $1 \mathrm{~m}$ in height. This estimate was based on visual inspection to identify unsampled larger individuals, but without ground verification it was difficult to ascertain if pockets of high seedling density were present in unvisited areas on steep slopes. No Eastern Hemlocks were present in the immediate vicinity.

We recorded the following data for each individual: spatial location as $\mathrm{x}$ and $\mathrm{y}$ coordinates, height, $\mathrm{dbh}$, and 3 indicators of disease - tree condition, number of

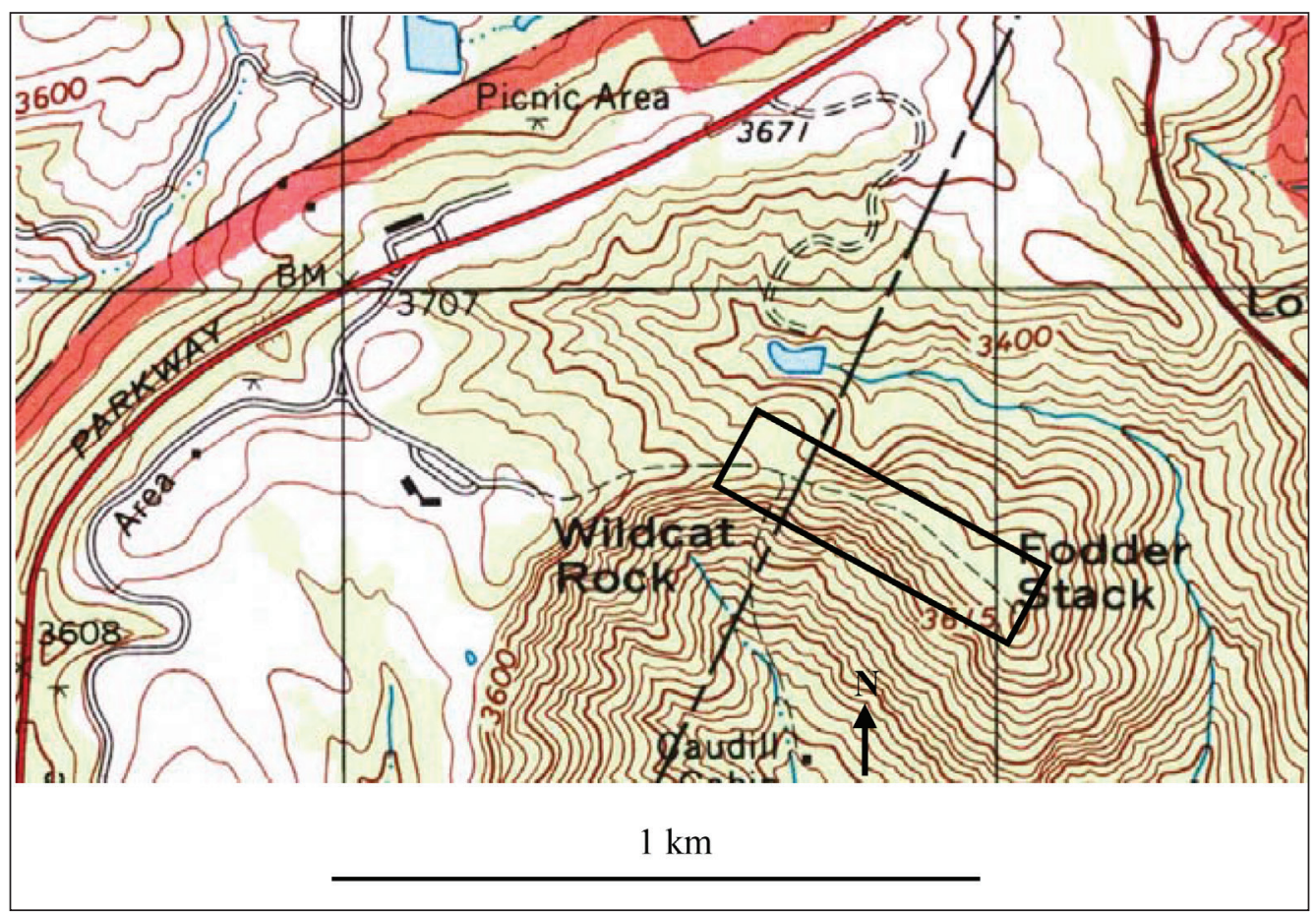

Figure 1. Field site, bounded by the black rectangle, located on a ridge in Doughton State Park, NC. Blue Ridge Parkway labeled as Parkway. Contour interval = $12.2 \mathrm{~m}(40 \mathrm{ft})$. US Geological Survey, Whitehead Quadrangle, NC [map]. Photorevised 1998. 1:24,000. 7.5-minute series. United States Department of the Interior, USGS, Reston, VA 1998. 
quadrants infested (for individuals $>0.30 \mathrm{~m}$ in height), and infestation density. We assessed tree condition on a 5-point scale corresponding generally to the proportion of the tree with healthy foliage, scaled in $20 \%$ increments. For ease of interpretation, we will refer to these categorical numerical values, ranging from high to low, as excellent, good, fair, poor, and near dead. The scale is similar to ones used in comparable studies (Eschtruth et al. 2006, Evans et al. 2011, Orwig and Foster 1998, Rentch et al. 2000, Royle and Lathrop 1997). We determined the number of quadrants of a tree infested based on a visual examination for HWA egg cases on accessible foliage in each of the cardinal directions. We scored the observation of any HWAs in the quadrant as positive regardless of density; the scale range was 0-4 quadrants. Infestation density was a visual estimate based on the density of egg cases graded on a 4-point scale with zero corresponding to no egg cases and 3 corresponding to confluence of egg cases along undersides of twigs. For ease of interpretation, we will refer to these categorical numerical values ranging from no infestation to dense infestation as no, light, moderate, and heavy infestations. We made our HWA estimates with the understanding that HWA distribution varies with tree-crown position (Evans and Gregoire 2007). As a group, the 3 disease-indicator traits provided estimates of the magnitude and distribution of insects on the tree and of the tree's overall condition. Two researchers assessed these 3 variables independently. In most cases, the results of separate assessments were identical. For those assessments that were not in agreement, values usually differed by no more than 1 scale unit, in which case consensus was arrived at after re-examination. When multiple researchers examined satellite images to assess canopy condition, separate assessments had a similar level of precision (Royle and Lathrop 1997). In the few instances where assessments differed by more than one scale unit, we conducted reassessments until we reached consensus.

\section{Data analysis}

We employed 2 approaches to understand spatial structure of the HWA infestation and the condition of Carolina Hemlocks, each applied to tree-height data and to data from each census year separately for each of the 3 disease-indicator variables. Tree height and dbh were strongly correlated (Pearson correlation coefficient $=0.94 ; P=0.001$ ). We used only tree height in our analyses because height data included all individuals, whereas dbh omitted those shorter than breast height. First, we conducted spatial autocorrelation to examine population-wide patterns of similarity by using Moran's I statistic as implemented with Spatial Analyses in Macroecology ( $v$ 4.0) software and running 1000 permutations to estimate significance (Rangel et al. 2010). We assigned individuals to 5 equal distance-classes to provide insight into the magnitude and sign of autocorrelations at different distances. Second, we conducted cluster analysis based on the scan statistic as carried out using SaTScan software to examine patterns of local aggregations (Kulldorff and Information Management Services, Inc. 2009). This method identifies clusters of individuals whose trait values are significantly higher or lower than the remainder of the population. In regard to HWA infestation, this approach generates clusters 
of relatively more or less infested individuals, and for tree condition, clusters of individuals in relatively better or poorer condition, hereafter referred to as health or disease clusters, respectively. We based analyses on an ordinal model with 1000 Monte Carlo simulations used to assess significance. When significant clusters of disease-indicator traits were identified, an analysis of frequencies was used to determine whether any size class was more common in the cluster compared to the remainder of the population. We assessed significance using Fisher's exact test of $2 \times 2$ contingency tables in which rows corresponded to the individuals either in or out of the cluster and columns represented the size class of interest versus individuals in all other size classes.

We conducted analyses of frequencies using Fisher's exact tests to determine whether there were significant temporal changes in the distribution of each disease indicator. First, all years were compared in a single analysis followed by pairwise comparisons of years. Separate analyses were conducted for each of the three disease indicators. For each year and each disease indicator, we also used exact tests to assess differences in the distribution of responses among height classes.

We used logistic regression to examine the influence and potential interactions of height and transect location on disease. Separate analyses were conducted on each of the 3 disease indicator variables for each of the 4 census years. Predictor variables were $\mathrm{x}$ and $\mathrm{y}$ coordinates and tree height class. Heights were aggregated into 4 categories as follows: $\leq 0.3 \mathrm{~m}, 0.3-2.4 \mathrm{~m}, 2.5-6.1 \mathrm{~m}$, and $>6.1 \mathrm{~m}$. With the caveat that Carolina Hemlocks can withstand long periods of time as slowgrowing understory plants, these height categories broadly correspond to, and for convenience are referred to, as seedlings, saplings, small trees, and large trees, respectively. We treated tree height class and each of the disease indicators as categorical variables and the transect $\mathrm{x}$ and $\mathrm{y}$ coordinates as continuous variables.

\section{Results}

The population age structure at Doughton Park had a negative exponential shape with a broad base comprised of 78 seedlings representing $48 \%$ of the population. Larger size classes each had progressively fewer individuals: 38 saplings $(23 \%)$, 28 small trees (17\%), and 20 large trees (12\%). At the onset of the study in 2007, impacts from HWA were minor: $68 \%$ and $30 \%$ of individuals were in excellent and good condition, respectively; $33 \%$ and $54 \%$ had no and light infestations, respectively; and $34 \%$ and $21 \%$ had 0 or 1 quadrant infested, respectively (Table 1 , Fig. 2). The 2 infestation indicators peaked in 2008 and then declined in each of the following 2 years while tree condition declined progressively. By $2010,50 \%$ of the individuals were in excellent or good condition, and $50 \%$ were in fair or poor condition (Fig. 2). Each year, seedlings had the highest proportion of individuals in excellent condition, while saplings tended to have the highest proportions in fair and poor condition (Fig. 3).

For each of the 3 disease indicators, the distribution of individuals among the response categories differed significantly between all pairs of years and when all 4 years were considered together $(P<0.001$ for each analysis). Similarly, each year 


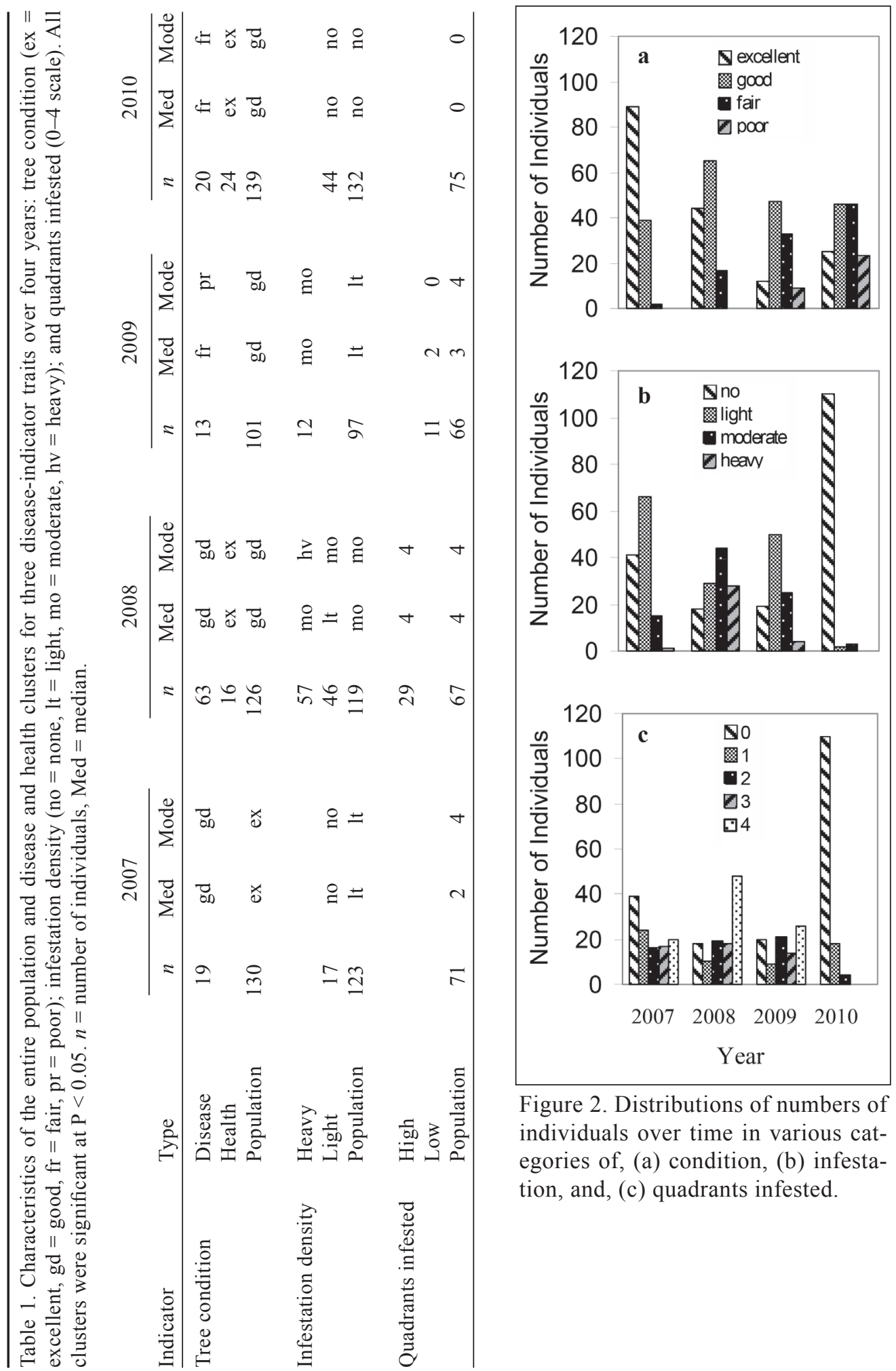


the response distributions of each disease indicator differed significantly among tree height classes $(P<0.001$ for each analysis) (Fig. 3).

An examination of individual tree responses to disease can provide insight into the rate of decline. Other than seedlings, only 1 tree died during the study: a 1.5$\mathrm{m}$ tall individual that began the study in the good condition class but each year dropped 1 condition class and was deceased by 2010. Seventeen trees declined from excellent to fair condition, a group that included individuals of all size classes except large trees. Only 6 of these declining trees had moderate to heavy infestations prior to reaching the fair condition class. Sixteen trees progressed to poor condition, 9 from excellent and 7 from good condition; 11 of the 16 were saplings. Six individuals maintained excellent condition for the 4-year duration: 5 seedlingsized individuals, and 1 large tree that was most isolated from the remainder of the population. We observed no HWA on that tree nor on 2 of the seedlings at any time.

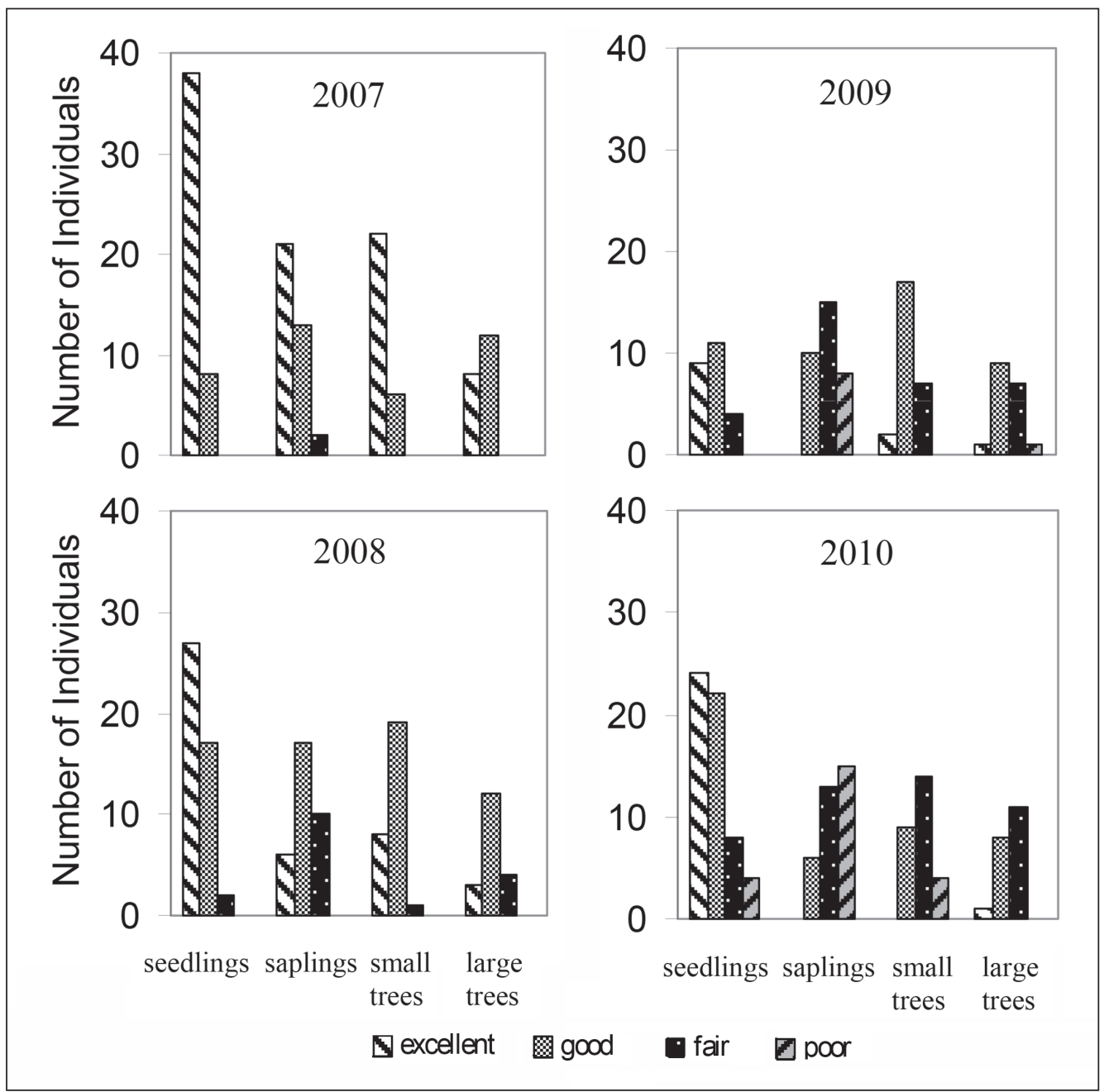

Figure 3. Distributions of individuals in four condition categories (excellent, good, fair , poor ) from 2007-2010. 


\section{Spatial patterns}

Spatial autocorrelation. There was a significant positive spatial autocorrelation in tree height among pairs of individuals at the farthest distance class (Moran's I = $0.37, P=0.03$ ). Thus, individuals farthest from each other were likely to be similar in height, an effect largely caused by some large trees at both ends of the transect. The far-distance effect disappeared when 3 large trees that were relatively isolated at the southeast end of the transect were removed from the analysis. Spatial autocorrelations for disease-indicator traits were not sensitive to the presence or absence of the isolated trees. In 2007, there were no significant autocorrelations for any of the 3 disease-indicator traits. However, by 2008 and 2009, all 3 disease-indicators had moderately strong, negative autocorrelations at the farthest distance class (Moran's $\mathrm{I}=-0.35$ to -0.41 ), a pattern that indicated individuals far from each other were likely to differ in condition and infestation characteristics. The duration of the autocorrelation for the far distance class was different among indicator traits, with infestation density losing significance after one year, while significance for number of quadrants infested persisted for 2 years, and the autocorrelation for tree condition decreased in strength but remained significant until 2010. For the nearest distance class, all 3 indicator-traits showed a small but significant positive autocorrelation that began in 2008 and lasted until 2009 (infestation density, number of quadrants infested) or 2010 (tree condition) (Moran's I $=0.02-0.04, P<0.01$ for each). The positive autocorrelation indicated individuals near each other were likely to be similar for the trait considered.

Cluster analysis of height. In 2007, 2008, and 2010, aggregations of seedlings in one region were manifested as seedling-dominated clusters of varying numbers of individuals (Table 2). Seedlings represented 76-91\% of the individuals in these clusters. In 2009, there was a cluster that had nearly equal representation of seedlings and saplings, and in 2010, there was a cluster dominated by saplings with lesser representation of small and large trees and an absence of seedlings (Table 2).

Cluster analysis of tree condition. At the first census, in 2007, a disease cluster was detected (Fig. 4). Over the 4 census years, the percentages of trees in excellent

Table 2. Characteristics of clusters for height (m). All clusters were significant at $P<0.05$. Mean $=$ cluster mean; $n=$ number of individuals in the cluster; SEM = standard error of the mean.

\begin{tabular}{|c|c|c|c|c|}
\hline \multirow[b]{2}{*}{ Trait/cluster Type } & \multicolumn{4}{|c|}{$\begin{array}{c}\text { Mean } \\
(n, \mathrm{SEM})\end{array}$} \\
\hline & 2007 & 2008 & 2009 & 2010 \\
\hline \multicolumn{5}{|l|}{ Height } \\
\hline Seedling-dominated & $\begin{array}{c}2.01 \\
(51,0.41)\end{array}$ & $\begin{array}{c}0.66 \\
(22,0.41)\end{array}$ & & $\begin{array}{c}1.10 \\
(42,0.33)\end{array}$ \\
\hline Seedling and sapling-dominated & & & $\begin{array}{c}0.67 \\
(18,0.14)\end{array}$ & \\
\hline No seedlings & & & & $\begin{array}{c}4.43 \\
(23,0.81)\end{array}$ \\
\hline Entire population & $\begin{array}{c}2.90 \\
(130,0.31)\end{array}$ & $\begin{array}{c}2.79 \\
(131,0.31)\end{array}$ & $\begin{array}{c}3.36 \\
(101,0.35)\end{array}$ & $\begin{array}{c}2.69 \\
(138,0.30)\end{array}$ \\
\hline
\end{tabular}




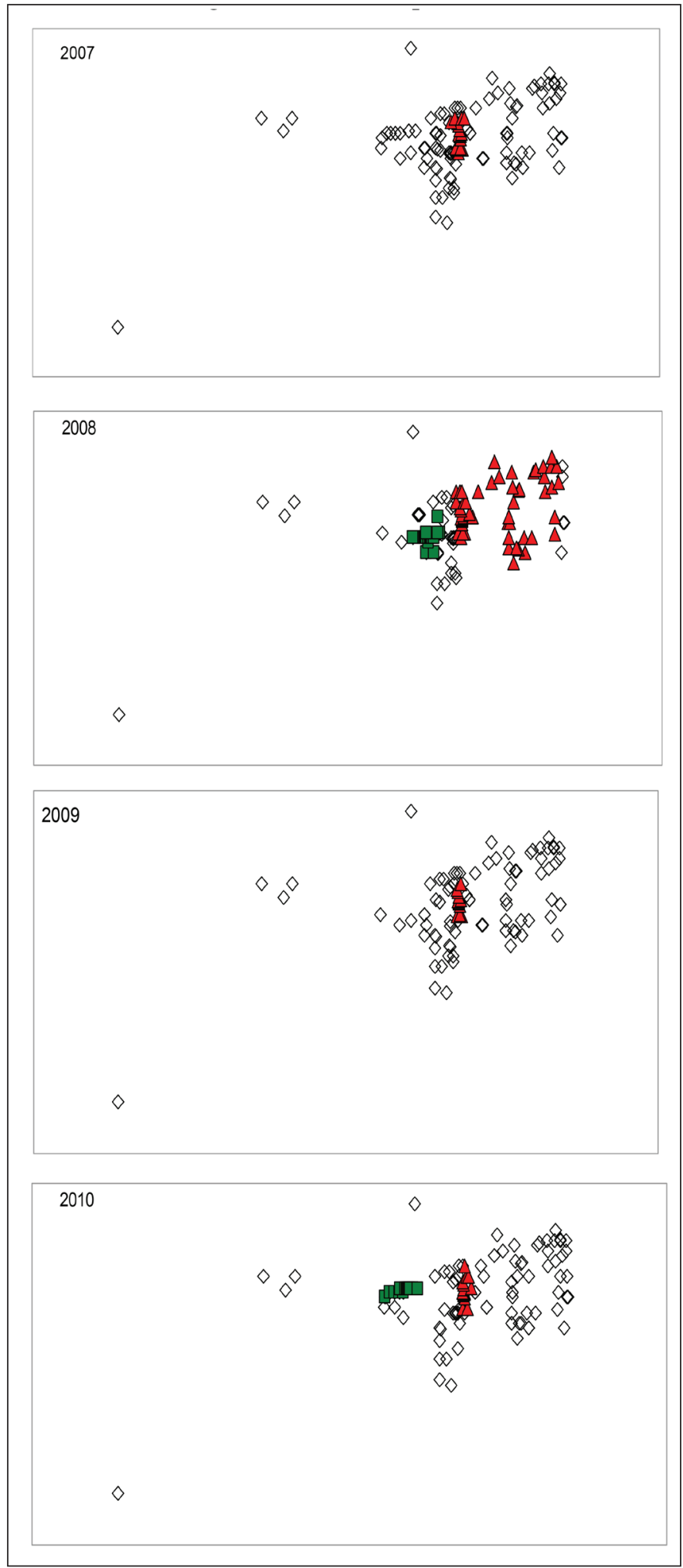

Figure 4. Plots showing locations of unclustered individuals in the population (open diamonds), individuals in disease clusters (red triangles), and individuals in health clusters (green squares) for 2007-2010. From left to right, the $\mathrm{x}$ axis represents a southeast to northwest transect. 
and good condition in this cluster declined from $21 \%$ and $67 \%$, respectively, to $0 \%$ and $5 \%$, respectively. The rate of decline in condition in the cluster outpaced that in the population as a whole, which declined from $38 \%$ and $30 \%$ in excellent and good conditions, respectively, to $18 \%$ and $32 \%$, respectively. The differences in the rates of decline were also reflected in differences in declines in the cluster and population medians and modes (Table 1). The disease cluster was numerically dominated by saplings and remained in a relatively stable location throughout the duration of the study, but its size increased dramatically in 2008 before returning to lower levels for the 2 ensuing years (Fig. 4). Over the 4 census years, saplings represented $40-60 \%$ of individuals in the disease cluster but only $25-33 \%$ of the population. The differences in sapling frequencies between the cluster and the remainder of the population were significant each year $(P<0.03$ each year).

In a different location, a health cluster appeared in 2008, it was not significant in 2009, but returned and was present in a similar location in 2010 (Table 2, Fig. 4). Seedlings comprised $100 \%$ and $79 \%$ of this cluster in 2008 and 2010 , respectively, during which time seedlings comprised $38 \%$ and $42 \%$ of the population, respectively. Each year, seedling frequencies were significantly higher in the cluster compared to the remainder of the population $(P<0.0001$ each year).

There was overlap in membership in the condition and height clusters. For example, $96 \%$ and $100 \%$ of the individuals in the 2008 and 2010 health clusters, respectively, were encompassed in the seedling-dominated height clusters present in those years, but the height clusters also included several individuals that were not part of the health cluster (Table 1). Similarly, in 2009, 77\% of the individuals in the disease cluster were part of the seedling and sapling-dominated height cluster, and in $2010,80 \%$ of the individuals in the disease cluster were members of the no seedlings height cluster (Table 2).

Cluster analysis of infestation density. In 2007, there was a cluster of uninfested to lightly infested individuals comprised of 13 seedlings and 4 large trees (Table 1). The majority of individuals in the population in 2008 were members of either a light or heavy infestation cluster, with 46 and 57 members representing $35 \%$ and $43 \%$ of the population, respectively. The location of the light and heavy infestation clusters corresponded to the southeast and northwest regions of the transect, respectively. A light infestation cluster of 44 individuals appeared again in 2010. Infestation densities peaked in 2008 when 27 individuals had heavy infestations (Table 1). Saplings comprised 17 of the individuals in this group that included only two seedlings and two mature trees. Of the 27 individuals with heavy infestations, 10 eventually declined to poor condition and another 10 to fair condition.

Cluster analysis of quadrants infested. After an absence of clusters for quadrants infested in 2007, in 2008 there was a cluster of 29 individuals with high numbers of quadrants infested (Table 1). In 2009, there was a small cluster of 11 individuals with relatively few quadrants infested comprised exclusively of large trees and located at the southeast end of the transect.

Rate of Decline. Rates of decline were not uniform among individuals in different size classes. Disease was most severely manifested in sapling-sized individuals 
as evidenced by the highest rate of decline in condition among size classes (Fig. 3). Moreover, saplings comprised a disproportionate share of the individuals in the disease cluster. For example, in 2008 when the disease cluster was at its maximum size, saplings represented $40 \%$ of the cluster but only $25 \%$ of the entire population.

Logistic regressions showed that height class was a significant predictor of tree condition and infestation density for 2008-2010, but in each of those years, there was also a significant interaction between height class and position on the transect $\mathrm{x}$-axis. In 2009, the numbers of quadrants infested similarly showed significance for height class and the height class by $\mathrm{x}$-axis interaction. The interaction shows that the magnitude of the disease indicator traits was dependent upon both the location of an individual and its size. Neither position on the transect y-axis nor any of the other potential interactions were significant for any of the disease indicators at any year.

\section{Discussion}

As a species with 2 of the 3 defining characteristics of rare species (Rabinowitz 1981), a narrow geographic range and a specialized habitat preference, Carolina Hemlock is likely more prone to local and global extinction than the more widespread Eastern Hemlock. Unlike Eastern Hemlock populations that are often ill-defined because they tend to follow water courses and mountain coves, Carolina Hemlock populations, which occur along ridges and outcroppings, tend to be more discrete and more isolated from each other (Humphrey 1989, Jetton et al. 2008, Rentch et al. 2000). Thus, for the third characteristic of rare species, low population density (Rabinowitz 1981), populations of Carolina Hemlock are often relatively small compared to the extensive areas dominated by Eastern Hemlock. In regard to disease, population isolation may decrease the transmission of pathogens from other populations, but once established, small population dynamics may lead to more rapid loss of population viability.

Aside from seedlings, only one individual died over the 4-year duration of the study. While no individuals progressed from excellent to poor condition, many declined from good to poor condition in as little as 3 years. At these rates of decline after an initial infestation, a minimum of 5 years is required for mortality, and most trees can be expected to die or reach an irreversible state of decline in 5-10 y. This estimate is greater than the 2-4-y time to death cited previously for Carolina Hemlock (Jetton et al. 2008), but it is consistent with the 7-y time span from infestation to mortality reported for Eastern Hemlock near the southern extent of the range (Ford et al. 2012). Very few plants other than seedlings remained HWA-free or in excellent condition, but as disease progressed in a non-random spatial pattern, at least 1 area had a concentration of individuals that were significantly healthier and less infested compared to the remainder of the population.

Population age and size structure may influence rates of hemlock decline. For example, in 2008, when the disease cluster was at its maximum size (Fig. 4), saplings represented $40 \%$ of the cluster but only $25 \%$ of the entire population. Stronger, more rapid impacts on smaller trees were similarly observed in Eastern Hemlock 
where suppressed, smaller trees declined more rapidly compared to canopy trees (Eschtruth et al. 2006, Orwig and Foster 1998, Rentch et al. 2009). At Doughton Park, a similar process leading to weakened individuals in the low canopy may have caused the most rapid decline in sapling-sized trees. Under an HWA-control strategy based on soil application of chemical pesticides, the sapling size class is logistically easiest and relatively inexpensive to treat, and if trees of this size are healthy with a full canopy (rather than weak from suppression) and are treated early in an infestation, they are more likely to respond to treatment than large trees (Webb et al. 2003).

In contrast, seedlings at Doughton Park were most likely to be free of HWA and in healthier condition. We noted the presence of new seedlings each year, a pattern that suggests on-going reproduction and recruitment rather than the episodic pattern noted in other populations (Humphrey 1989, Rentch 2000). Moreover, seedlings dominated the clusters of healthy individuals. For example, the health cluster of 2010 included 19 of 24 seedlings (79\%) while seedlings represented only $25 \%$ of the population (Table 1). However, health clusters were not exclusively seedlings - 3 large trees were also part of the 2010 health cluster. Seedling-sized individuals appeared to be the least likely size class to experience severe infestations, in part because there was some seedling turnover each year, with deaths and new recruitment. While studies of hemlock decline rarely report seedling condition, abundance of Eastern Hemlock seedlings at sites in NJ and PA increased after HWA infestation, but annual fluctuations in recruitment were also noted (Eschtruth et al. 2006). In riparian sites across the range of Eastern Hemlock, seedling density varied from zero to over $15,000 /$ ha, with no seedlings noted for the three North Carolina populations surveyed (Evans et al. 2011).

Population age structure can provide insight into the history of populations, but this information was also deemed important to Carolina Hemlock gene conservation efforts (Jetton et al. 2008). Each of the limited number of populations of Carolina Hemlock for which age or size structure has been studied included relatively old trees (>100 years of age; Humphrey 1989, Rentch et al. 2000). However, age structure among these populations may vary widely and range from a relative dearth or absence of seedlings to a preponderance of seedlings. At Bluff Mountain, NC, clumps of even-aged individuals suggested episodic recruitment, but the age structure at 3 of 4 sites indicated populations were stable (Humphrey 1989). Whereas no seedlings were found at Bottom Creek Gorge, VA, and the tree size distribution was nearly normal, that population was also thought to undergo episodic recruitment and was considered stable (Rentch et al. 2000). A more recent study of Carolina Hemlocks showed 2 populations in eastern Tennessee with an underrepresentation of seedlings and 2 populations in western North Carolina with stable size distributions (Levy et al. 2008).

Even before major declines in Carolina Hemlock populations were noted, both HWA infestation and hemlock decline occurred in foci rather than randomly in populations (Levy et al. 2008). At Doughton Park, the size of the infestation cluster increased rapidly over time but the cluster then disappeared (Table 1). In contrast, 
the disease cluster, while peaking in size in 2008 , continued to appear as a significant cluster for the duration of the study. It should be noted that cluster detection is a relative metric. Thus, while the condition of trees in the disease cluster continued to decline, the reduction in cluster size was not caused by a reversal of disease but was most likely a consequence of a trend to declining health across the remainder of the population. At the time that the disease cluster reached maximum size in 2008, a cluster of relatively healthy plants appeared in a different region of the population, and this cluster was again apparent 2010 (Table 1, Fig. 4).

As hemlocks decline, sectors of their canopies are lost, which reduces amounts of new growth. Because HWA prefers new growth (Young et al. 1995), a decrease in food quality is the likely cause of the decline in the HWA population. Hence, changes in the hemlock hosts may account for the rapid increase and then the rapid decline in the magnitude of the infestation density and size of the infestation cluster. As HWA became widespread and reached high densities in the population, previously unimpacted trees began to experience decline. Thus, as the conditions of trees outside the disease cluster approached those within the cluster, the cluster appeared to shrink in size, but the population as a whole continued to decline.

Rates of hemlock decline cannot be estimated from examinations of populations at single time points (Evans et al. 2011, Levy et al. 2008). However, in a detailed long-term study of Eastern Hemlock initiated prior to HWA infestation, the rate of decline of Eastern Hemlock was evaluated over a 10-year period at two sites in the Delaware Water Gap National Recreation Area, NJ/PA (Eschtruth et al. 2006). After initial detection of HWA, there was a lag of several years before infestations reached an occurrence rate of $>5 \%$ of twigs infested. At 1 site, the percentage of trees that died or showed severe decline increased approximately $30 \%$ in one year (1999-2000), from $<5 \%$ to $>35 \%$, but at the second site, trees in those 2 condition categories remained below $10 \%$ for the duration of the study. While the rate of decline may have both site-specific and species-specific components, the effects of different site characteristics on decline are not clear (Rentch et al. 2009). Rather, levels of infestation were the most accurate predictors of decline (Rentch et al. 2009).

Landscape-scale analyses, such as those based on data from remote sensing, have been used to document changes in canopy cover and differences among sites experiencing hemlock decline (Koch et al. 2006, Royle and Lathrop 1997). In combination with spatial autocorrelation analysis, this approach showed populations in proximity tended to be similar in levels of infestation and decline in condition (Orwig et al. 2013). However, a more detailed ground-based evaluation of individuals is usually necessary to uncover patterns of disease progression within populations. The analyses at Doughton Park showed that there are also spatial patterns of infestation and disease within a population. Thus, pattern analysis at both the landscape and population level may be useful and complementary in guiding management strategies (Vose et al. 2013). 


\section{Acknowledgments}

We thank J. Donaldson, R. Ingram, and an anonymous reviewer for helpful comments on the manuscript, the National Park Service for permission to conduct this work on their property, and the Appalachian Highlands Science Learning Center for initial funding.

\section{Literature Cited}

Bentz, S.E., L.G. Riedel, M.R. Pooler, and A.M. Townsend. 2002. Hybridization and selfcompatibility in controlled pollinations of eastern North American and Asian hemlock species. Journal of Arboriculture 28:200-205.

Eschtruth, A.K., N.L. Cleavitt, J.J. Battles, R.A. Evans, and T.J. Fahey. 2006. Vegetation dynamics in declining Eastern Hemlock stands: 9 years of forest response to Hemlock Woolly Adelgid infestation. Canadian Journal of Forest Research 36:1435-1450.

Evans, A.M., and T.G. Gregoire. 2007. The tree-crown distribution of Hemlock Woolly Adelgid, Adelges tsugae (Hem., Adelgidae) from randomized branch sampling. Journal of Applied Entomology 131:26-33.

Evans, D.M., W.M. Aust, C.A. Dolloff, B.S. Templeton, and J.A. Peterson. 2011. Eastern Hemlock decline in riparian areas from Maine to Alabama. Northern Journal of Applied Forestry 28:97-104.

Ford, C.R., K.J. Elliott, B.D. Clinton, B.D. Kloeppel, and J.M. Vose. 2012. Forest dynamics following Eastern Hemlock mortality in the southern Appalachians. Oikos 121:523-536.

Humphrey, L.D. 1989. Life-history traits of Tsuga caroliniana Engelm. (Carolina Hemlock) and its role in community dynamics. Castanea 54:172-190.

Jetton, R.M., W.S. Dvorak, and W.A. Whittier. 2008. Ecological and genetic factors that define the natural distribution of Carolina Hemlock in the southeastern United States and their role in ex situ conservation. Forest Ecology and Management 255:3212-3221.

Koch, F.H., H.M. Cheshire, and H.A. Devine. 2006. Landscape-scale prediction of Hemlock Woolly Adelgid, Adelges tsugae (Homoptera: Adelgidae), infestation in the southern Appalachian Mountains. Environmental Entomology 35:1313-1323.

Kulldorff, M., and Information Management Services, Inc. 2009. SaTScan ${ }^{\mathrm{TM}}$ v8.0: Software for the spatial and space-time scan statistics. Available online at http://www.satscan. org/. Accessed 25 January 2013.

LePage, B.A. 2003. A new species of Tsuga (Pinaceae) from the middle Eocene of Axel Heiberg Island, Canada, and an assessment of the evolution and biogeographical history of the genus. Botanical Journal of the Linnean Society 141:257-296.

Levy, F., J. Baker, K. Chen, G. Cooke, Y-S. Liu, E.S. Walker, and T. McDowell. 2008. Patterns of spread of Hemlock Woolly Adelgid. Pp. 168-176, In B. Onken and R. Readon (Eds.). Proceedings of the $4^{\text {th }}$ Hemlock Woolly Adelgid Symposium, Hartford, CT. 339 pp.

Orwig, D.A., and D.R. Foster. 1998. Forest response to the introduced Hemlock Woolly Adelgid in southern New England, USA. Journal of the Torrey Botanical Society 125:60-73.

Orwig, D.A., D.R. Foster, and D.L. Mausel. 2013. Landscape patterns of hemlock decline in New England due to the introduced Hemlock Woolly Adelgid. Journal of Biogeography 29:1475-1487.

Pooler, M.R., L.G. Riedel, S.E. Bentz, and A.M. Townsend. 2002. Molecular markers used to verify interspecific hybridization between hemlock (Tsuga) species. Journal of the American Society for Horticultural Science 127:623-627. 
Rabinowitz, D. 1981. Seven forms of rarity. Pp. 205-217, In H. Synge (Ed.) The Biological Aspects of Rare Plant Conservation. John Wiley and Sons, New York, NY. 558 pp.

Rangel, T.F., J.A. Diniz-Filho, and L.M. Bini. 2010. SAM: A comprehensive application for spatial analysis in macroecology. Ecography 33:46-50.

Rentch, J.S., H.S. Adams, R.B. Coxe, and S.L. Stephenson. 2000. An ecological study of a Carolina Hemlock (Tsuga caroliniana) community in Southwestern Virginia. Castanea 65:1-8.

Rentch, J., M.A. Fajvan, R.A. Evans, and B. Onken. 2009. Using dendrochronology to model Hemlock Woolly Adelgid effects on Eastern Hemlock growth and vulnerability. Biological Invasions 11:551-563.

Royle, D.D., and R.G. Lathrop. 1997. Monitoring hemlock forest health in New Jersey using Landsat TM data and change detection techniques. Forest Science 43:327-335.

Vose, J.M., D.N. Wear, A.E. Mayfield III, and C. Dana Nelson. 2013. Hemlock Woolly Adelgid in the southern Appalachians: Control strategies, ecological impacts, and potential management responses. Forest Ecology and Management 291:209-219.

Webb, R.E., J.R. Frank, and M.J. Raupp. 2003. Eastern Hemlock recovery from Hemlock Woolly Adelgid damage following imidacloprid therapy. Journal of Arboriculture 29:298-301.

Young, R.F., K.S. Shields, and G.P. Berlyn. 1995. Hemlock Woolly Adelgid (Homoptera: Adelgidae): Stylet bundle insertion and feeding sites. Annals of the Entomological Society of America 88:827-835. 